\title{
PATRIMONIO MINERO-INDUSTRIAL EN CASTILLA-LA MANCHA: EL ÁREA ALMADÉN-PUERTOLLANO
}

\author{
María del Carmen Cañizares Ruiz \\ Departamento de Geografía y Ordenación del Territorio \\ Universidad de Castilla-La Mancha
}

\section{RESUMEN}

El sector suroccidental de Castilla-La Mancha, donde localizamos el área de Almadén-Puertollano, se ha caracterizado, tradicionalmente, por su riqueza minera (plomo, plata, cinc, mercurio, carbón o pizarras bituminosas) así como por las actividades industriales vinculadas a la transformación de los minerales. De estas actividades se derivan, en la actualidad, diversos elementos que componen un patrimonio minero-industrial de gran valor, formado, principalmente, por castilletes (metálicos y de mampostería) utilizados para la extracción del mineral así como por diversos restos de maquinaría (hornos, por ejemplo) y algunas edificaciones (salas de máquinas, etc.). La situación de abandono y escasa valoración a la que están sometidos son objeto de este artículo. En él se analizan las posibilidades de conservación-rehabilitación así como su rentabilización como recursos en una zona de economía desfavorecida, para finalizar haciendo referencia a las perspectivas de futuro y a su progresiva puesta en valor.

Palabras clave: patrimonio minero-industrial, recurso, puesta en valor.

\section{RÉSUMÉ}

Le secteur sudoccidental de Castilla-La Mancha, où nos avons localisé l'area de Almaden-Puertollano, s'est caracterisé traditionnellement par sa richese minière (du plomb, de l'argent, du zinc, du charbon et des ardoises bituminoises) aussi que les activités industrielles liés a la transformation des minérals. De ces activités se demarquent, aujourd'hui, plusieurs elements qui composent un patrimoine minièr-industriel de grand valeur qui se produit des structures (métalliques et de maçonnerie) qui sont utilisés par l'extraction du mineral aussi que par plusieurs restes de machinerie (des fours, par exemple) et des quelques bâtiments (des salles de machines, etc.). La situation d'abandon et la sousestimation a qui se sont soumis ce sont l'objet de cet article. On s'analisent les possibilités de conservation-rehabilitation comme recours dans une zone d'économie défavorable, pour concluire fait référence a des perspectives de futur et a sa progressive mise en valeur.

Mots clés: patrimoine minier-industriel, recours, mise en valeur. 


\section{Introducción: el creciente interés por el patrimonio minero-industrial}

En los últimos años, caracterizados por múltiples transformaciones socioeconómicas, hemos asistido a un proceso centrado en el creciente interés que se le ha prestado al patrimonio en general, y de forma concreta al patrimonio de origen minero e industrial. Interés que procede tanto del marco institucional como del puramente académico y científico. Es necesario relacionar estos hechos con los cambios experimentados por el propio concepto de patrimonio al concedérsele un carácter cada vez más amplio pues ya no se atiende exclusivamente al «monumento» con valor histórico-artístico sino a los «bienes de interés cultural»; y sobre todo, más social, al revalorizar el componente cultural que tiene como parte de la herencia cultural de determinados grupos sociales. De hecho, «desborda su utilización conceptual restringida para convertirse en un derecho de la colectividad» (Suárez-Inclán, 1998: 71).

De ahí que hoy contemplemos múltiples formas de patrimonio, algunas con un claro componente territorial, entre las que en este caso hemos elegido aquellas vinculadas a las actividades mineras e industriales en un área concreta de la región castellano-manchega. Lo componen todo el conjunto de restos, dignos de valoración, heredados de actividades desarrolladas en el pasado (históricos) o que lo han hecho en el período contemporáneo. Testimonios materiales, en su mayor parte, que constituyen la base del patrimonio industrial, como tradicionalmente se le denomina, a los que se añaden otros inmateriales que identifican los modos de vida de una población y que, de forma conjunta «se aceptan hoy como un elemento importante del patrimonio cultural al que se le reconoce un valor material y social, no siempre exento de cierto interés artístico, cuya conservación, protección y estudio se hacen imprescindibles para la comprensión de la sociedad industrial contemporánea» (Benito del Pozo, 1998: 171).

$\mathrm{Su}$ reconocimiento como objeto de estudio esta directamente vinculado, en primer lugar, a la proliferación de museos técnicos a finales del siglo XIX en Europa, cuyo «objetivo inicial se centraba en el estudio, la salvaguarda y conservación de máquinas, herramientas y utensilios de producción»(Alonso, 1992: 68). Pero, para algunos autores (Santacreu, 1992; Francescutti, 1993; Benito del Pozo, 1996), la fecha simbólica del comienzo del movimiento por la defensa del patrimonio industrial se fija, más recientemente, en 1962. Año en el que la destrucción de la estación ferroviaria londinense de Euston (edificio neoclásico construido entre 1835 y 1839) desencadenó una enorme conmoción que movilizó las conciencias tanto de los vecinos como de los técnicos y de los agentes sociales y económicos.

A lo largo del siglo XX, su temática se amplía a la arquitectura vernácula y a sus tradiciones constructivas y continúa apoyándose en el notable impulso que le ofrece el desarrollo de la Museografía de la Historia de la Ciencia y de la Técnica. Especialmente destacable es la creación de museos asociados a instalaciones industriales obsoletas como sucede en Alemania con el Deutches Museum von Meisterwerken der Naturwissenchaft und Technik de Munich o en Suecia con el Eskilstuna, antigua ferrería. Actuaciones que favorecieron el conocimiento de la historia de la tecnología, imprescindible para una correcta valoración de este patrimonio (Riera y Tuebols, 1996: 35).

En la segunda mitad de siglo se plantean varias vías para el estudio y la recuperación del patrimonio industrial que se materializan en actuaciones concretas. De ellas, son ejemplares por su distinta concepción de la protección y el uso de los restos de la industrialización, las siguientes (Santacreu, 1992: 15): 1. La creación del Centro de Archivos 
Históricos del Museo Alemán de la Mina de Bochum (Alemania), que se acompaña de dos museos técnicos (el de la mina y el de los ferrocarriles) manteniendo diversos restos de las explotaciones como el pozo Zollen 2/4. 2. Las realizaciones del Museo del Valle de Ironbridge (Gran Bretaña) donde se instala un parque-museo en los parajes que albergaron yacimientos de carbón y las fundiciones de hierro correspondientes a la cuenca de Coalbrookdale, destacando la restauración de un puente de hierro, The Iron Bridge (1779) y la creación de un museo del hierro y del museo al aire libre de Blits Hills. 3. La constitución, en los años 70, del Écomusée de Le Creusot-Montceau-les-Mines (Francia) es un intento de ofrecer una dimensión más social a la conservación del patrimonio industrial al albergar una zona geográfica entera que conforma, en sí misma, un documento sobre la industrialización en la que sobresale el Museo del Hombre y de la Industria. 4. Finalmente, el Museo de la Mina de Carbón de Argenteau-Trimbleur, en Blegny-Trimbleur, en Liége (Bélgica), localizado sobre una mina cerrada recientemente (1980), hoy reconvertida en complejo turístico.

Desde mediados de siglo se multiplican, de la misma forma, las iniciativas institucionales en favor de la preservación de este tipo de elementos. Como ejemplo individual más sobresaliente, el Reino Unido se convierte en sede del Council British Archaeology en 1945 y del The National Survey of Industrial Monuments en 1959 con la finalidad de preservar los monumentos industriales. A escala mundial se crea UNESCO-ICOMOS (International Council on Monuments and Sites) a mediados de los 60 como órgano internacional para la documentación sobre la restauración y la conservación del patrimonio monumental. Algunos años mas tarde, destacaría, también, la creación del The International Committee for the Conservation of the Industrial Heritage como foro de debate sobre la teoría, documentación y conservación del patrimonio industrial. En el último cuarto del siglo XX, la crisis daría paso a nuevas ideas y un buen exponente es la Recommandation relative a l'archeologie industrielle que realiza la Asamblea Parlamentaria del Consejo de Europa en 1975 así como las sucesivas Conferencias Europeas de Ministros responsables del Patrimonio Arquitectónico en las que estos elementos han conseguido una considerable revalorización.

Progresivamente, por tanto, se va consolidando una nueva disciplina, hoy comúnmente aceptada, a la que en algunos casos se la ha denominado «arqueología industrial» y que presenta un claro carácter pluridisciplinar. En nuestro caso y desde el enfoque que nos ofrece la disciplina geográfica, evitaremos el término arqueología industrial por su carácter eminentemente metodológico y sus referencias inseparables a los procesos productivos obsoletos, cuyo límite temporal a menudo finaliza cuando la tecnología deja de ser utilizada y es reemplazada por otra, privilegiando el de patrimonio minero-industrial al incluir en él procesos aún en funcionamiento, también depositarios de la memoria colectiva. En este sentido, aunque la mayor parte de los elementos se corresponden con actividades abandonadas, algunos otros se mantienen, permitiendo analizar «in situ» el propio proceso productivo.

En España, la evolución teórica y metodológica ha sido algo más lenta aunque no demasiado alejada de las corrientes europeas. Salvo excepciones como la reconstrucción de la Ferrería de la Mirándola (siglo XVI) en Legazpi (Guipúzcoa) en 1952, «para encontrar (...) antecedentes de las primeras tareas de catalogación del patrimonio edificado que incluyeran instalaciones de los ámbitos industrial y agropecuario debemos esperar hasta finales de los sesenta y principios de los setenta» (Herce y Otros, 1998: 13). Hoy se consolidan algunos ejemplos dignos de mención como son el Parque Minero de Río Tinto 
(1992), en Huelva, que reutiliza las minas de cobre después de la crisis, y el Museo de la Minería y de la Industria de Asturias en la cuenca carbonífera de El Entrego (1994), en Oviedo. Ambas actuaciones, a las que han sucedido otras diversas, persiguen un doble objetivo: «conservar el patrimonio cultural e histórico que las cuencas mineras representan $\mathrm{y}$, por otra parte, buscar alternativas que eviten o cuanto menos retrasen, el desmoronamiento económico del patrimonio minero» (García, 1998: 56). En los últimos años es destacable, también, el creciente interés demostrado por el sector universitario a través del fomento de catálogos e inventarios (Benito del Pozo, 2002: 219).

\section{Minería, industria y patrimonio en Castilla-La Mancha}

El proceso de industrialización en España, y en general en las zonas avanzadas, se ha caracterizado por el paso de unas fases iniciales o preindustriales de producción casi artesanal, a otras propiamente industriales en las que el sector secundario manifiesta un intenso crecimiento, para finalizar en la etapa postindustrial caracterizada por las reestructuraciones posteriores a la «crisis del petróleo», a partir de mediados de los años 70.

En Castilla-La Mancha, las primeras fases correspondientes a la etapa denominada preindustrial han estado íntimamente vinculadas a la intervención pública a través de las Reales Fábricas del siglo XVIII, basadas en la transformación de recursos naturales (lana, metales) cuya vida fue corta por las numerosas dificultades que encontraron en un entorno tan poco desarrollado como éste. Junto a ellas, la minería, practicada desde época prerromana, alcanza su mayor auge en el siglo XIX con las extracciones de cinabrio (Almadén), plata (Hiendelaencina), azufre (Hellín) o carbón (Puertollano) (Pardo, 2000), convirtiéndose, más adelante, en «el subsector más importante de la actividad industrial en la región» (Panadero y Pillet, 1999: 319). Situación reforzada por la industrialización del área de Puertollano (Ciudad Real) de orientación petroquímica y termoeléctrica, único ámbito en el que se ubica la industria pesada.

Sin embargo, a lo largo del siglo XX, esta región manifiesta muy poco desarrollo del sector secundario debido a su carácter periférico y sólo polariza sus actividades en función de recursos locales, principalmente centrados en la industria agroalimentaria (Carrera, 1986) y manufacturera, ambas caracterizadas por el minifundismo empresarial. Por ello sus repercusiones sociales y territoriales fueron muy limitadas y se redujeron a las áreas urbanas y a algunas especializadas de la llanura interior. Se trató, pues, de un débil proceso industrializador justificado en varias causas entre las que se encuentran los escasos niveles de capitalización agraria, la fuerte desarticulación del territorio regional, el débil mercado de consumo, la existencia de mano de obra poco cualificada y la limitada eficacia de las políticas de planificación industrial (Méndez, 2001: 214).

Tras la crisis de 1973 y la correspondiente reconversión que determina el período actual, las actividades tradicionales vinculadas a la minería y a determinados tipos de industria como la transformación de minerales y metales o las mecánicas decaen, manifestándose importantes pérdidas de empleo, mientras que las pequeñas empresas de manufacturas acusan en menor medida sus efectos. A pesar de ello, el desarrollo de la industria en el período de la recuperación, después de 1985, sitúa a esta región a la cabeza del crecimiento industrial en España (Pardo, 1996). La reorganización territorial de las actividades industriales, los procesos de descentralización y la revalorización de las áreas periféricas así como la proliferación de iniciativas de desarrollo endógeno a partir de la crisis convierten a la comunidad castellano-manchega en un espacio idóneo para el desarro- 
llo de estos procesos, debido a las ventajas competitivas que le aporta su situación respecto a la aglomeración madrileña y su posición estratégica entre el eje de crecimiento mediterráneo y Andalucía (Méndez y Carrera, 1999: 144). Así, manteniendo su estructura sectorial interna, basada en la especialización en sectores maduros, de demanda media o débil, para bienes intermedios o de consumo final (textil-confección, madera-mueble, cuero-calzado) junto a la alimentación, consolida un crecimiento industrial lento y tardío a partir de los nuevos espacios emergentes, protagonistas del «cambio industrial» que ha caracterizado el final de siglo.

Del declive de algunas actividades, en general debido a razones de viabilidad económica, así como de la pervivencia de determinados procesos productivos encontramos, actualmente, diversos vestigios en variable estado de conservación que se concretan en herramientas, edificaciones, maquinaria, etc. (restos materiales) así como en modos de vida o conocimientos técnicos (restos inmateriales). La tipología al respecto permite establecer distintos grupos en función de las materias primas utilizadas y así encontramos elementos relacionados con la producción de energía (molinos de viento, molinos hidráulicos, fábricas de luz), con la minería (estructuras, edificaciones), con la agroindustria (bodegas, almazaras), con la transformación de los metales y las industrias mecánicas (ferrerías, fábricas de metales) y con la fabricación de materiales de construcción (fábricas de ladrillo, caleras, etc.). En conjunto, forman parte de una cultura territorial que, ahora es considerada como un factor generador de riqueza (cultura productiva) especialmente valorado en aquellos espacios más desfavorecidos o en declive por su capacidad de generar empleo y de potenciar el interés sobre un territorio (Comisión Europea, 1998), como ocurre en el área escogida en este caso.

Por tanto, fruto del desarrollo de las actividades vinculadas a la minería y a la industria en Castilla-La Mancha el propio territorio alberga un patrimonio cultural específico. Es el Patrimonio de origen Minero e Industrial que se compone de los restos materiales e inmateriales heredados de las actividades industriales que forman parte de la identidad cultural de una determinada población, además de responder a un determinado sistema tecnológico. Debido a que se vincula con dos tipos de actividades, en muchas ocasiones es extremadamente difícil separar lo propiamente minero de lo industrial, razón por la que consideramos más correcto utilizar el término minero-industrial (Cañizares, 2002: 495) y no únicamente industrial (IPH, 2000) para no establecer limitación alguna.

\section{El patrimonio minero-industrial en el área Almadén-Puertollano}

\subsection{Las características geográficas del territorio}

El territorio seleccionado para analizar con cierta profundidad la caracterización del patrimonio minero-industrial se corresponde con el sector suroccidental de la provincia de Ciudad Real, y de la propia región castellano-manchega. En él diferenciamos tres grandes zonas: la Comarca de Almadén, en la que sobresalen los términos de Almadén y Almadenejos, con el núcleo de Almadén como cabecera comarcal; el Valle de Alcudia-Sierra Madrona caracterizado por albergar varios términos entre los que destaca el de Almodóvar del Campo, junto a los de Brazatortas, Cabezarrubias del Puerto, Hinojosas de Calatrava o Mestanza, entre otros; y, finalmente, el Área de Puertollano que identifica el término municipal del mismo nombre en el que encontramos el único asentamiento urbano de esta zona. 
El medio natural se identifica, mayoritariamente, con la región conocida como Valle de Alcudia-Sierra Morena Oriental (García Rayego, 1997), aunque algunos términos municipales aquí incluidos se enmarcarían dentro del Campo de Calatrava (Villamayor de Calatrava, Argamasilla de Calatrava y Puertollano). Constituye un claro ejemplo de relieve apalachense, caracterizado por la sucesión de sierras y depresiones que configuran un espacio geográfico de montaña media, donde encontramos, también, algunos fenómenos de volcanismo. Sin duda, los aspectos geológicos destacan a la hora de explicar la profusión de minerales en esta zona. Esta región se inserta en el Macizo Hercínico Ibérico, siendo sus componentes fundamentales los roquedos muy antiguos procedentes del Precámbrico Superior y del Paleozoico (Inferior y Medio, sobre todo) que se levantaron durante la Tectónica Hercínica y que desde entonces están siendo sometidos a procesos erosivos. Predominan, por tanto, cuarcitas, areniscas, pizarras, esquistos y conglomerados con metamorfismo de bajo grado (García Rayego, 1999: 12). La notable riqueza de depósitos minerales que existe en esta zona se concreta en filones de relleno en los que se han encontrado plomo, cinc, plata, hulla o bismuto, a los que se añaden los esteroides correspondientes a los yacimientos de mercurio en Almadén (Palero, 2000: 26 y ss.).

Su clima es templado y está determinado por la moderación térmica general, altas temperaturas veraniegas y una cierta continentalidad que se acusa en los importantes contrastes térmicos tanto anuales como diarios, aspectos a los que se añade un irregular reparto de las precipitaciones. El monte mediterráneo sobre sustrato silíceo da identidad al paisaje vegetal en el que destacan variados complejos vegetales, destacando el del encinar en las áreas más secas, el del alcornocal en las que son algo más húmedas, así como los del quejigar y el del robledal, en espacios más frescos y húmedos. Las depresiones presentan un rasgo particular, el adehesamiento, donde la representación arbórea fundamental es la encina. Aparecen, también, formaciones vegetales de ribera entre las que destacan las fresnedas, saucedas y alisedas (García Rayego, 1999).

Desde el punto de vista humano encontramos un territorio poco poblado y escasamente desarrollado, salvo excepciones, que ha estado tradicionalmente unido a las actividades agropecuarias. Dominado históricamente por la Orden de Calatrava, su riqueza en pastos favoreció el paso de los ganados trashumantes de La Mesta. Sin embargo, nunca rentabilizó sus materias primas ya que, generalmente, fueron explotadas desde el exterior. Muy afectado, después, por las desamortizaciones del siglo XVIII y XIX, se convirtió en dominio de los grandes propietarios absentistas que seccionaron el territorio en grandes fincas. Actualmente el núcleo principal y organizador es Puertollano con cerca de 50.000 habitantes, constituyendo el resto un conjunto de asentamientos semirurales y rurales fuertemente dañados por la emigración entre los que sobresalen Almodóvar del Campo y Almadén. Las actividades económicas predominantes continúan estando relacionadas con el sector primario, principalmente ganadería y aprovechamiento cinegético, puesto que la industrialización se reduce al área de Puertollano en la que se combinó la extracción de carbón con la industria petroquímica, producciones que aún se mantienen, y al núcleo de Almadén donde agoniza la minería del cinabrio, hoy en crisis.

La presencia de materias primas tan valiosas como las que hemos citado ha sido fundamental no solo para las explotaciones mineras sino para desarrollar actividades industriales vinculadas a ellas, como analizaremos mas adelante. Hoy la presencia de numerosos restos tanto de la minería como de la industria, testimonian el pasado socioeconómico de la población que habita estas zonas. Por ello consideramos que «no hay posibilidad de entender estos restos industriales fuera de una perspectiva territorial» (Ortega, 1998: 37). Una perspectiva, 
sin duda, infravalorada ya que el territorio, construido a partir de un conjunto de estructuras urbanas, rurales y socioeconómicas heredadas, era, hasta hace relativamente poco tiempo, despreciado en los estudios sobre patrimonio (Campesino, 1998). Hoy, en su conjunto, es cada vez mas valorado como recurso patrimonial. La preocupación excesiva de contemplarlo como sustrato de las actividades económicas había impedido analizarlo en su dimensión global e incorporarlo a los procesos de desarrollo local. Actualmente, numerosos estudios reivindican el territorio como patrimonio cultural, recurso y producto, puesto que en él se reconocen elementos edificados y no edificados que podemos identificar con una determinada forma de organización social. El patrimonio minero-industrial que ahora analizamos no sería sino una parte, un patrimonio específico, inserto en el propio patrimonio territorial.

\subsection{Breve caracterización de las actividades mineras e industriales}

El origen de las explotaciones mineras en este territorio se remonta a época preromana con la extracción del cinabrio (siglo IV a. de C.), aunque serían los romanos los que las iniciaran de una forma destacada, no sólo la explotación de este mineral (del cual utilizaban el bermellón para tintes) sino las extracciones de plata y plomo en el Valle de Alcudia (Mina Diógenes, San Quintín). Tras el freno que supuso la dominación visigoda, los árabes revitalizaron la minería en Almadén, fundamental después del Descubrimiento de América cuando, en los primeros siglos de la Edad Moderna, diversos factores la favorecieran tales como las guerras (cañones, balas, etc.), el incipiente desarrollo urbano (hierro para la clavazón), el proceso de colonización del territorio y el crecimiento demográfico (aperos de labranza, etc.) o el arraigo de la pañería rural (bermellón para tintes, etc.) (Gómez, 2000: 100-101). Además, a partir de 1555, las exportaciones de mercurio (cinabrio fundido) al Nuevo Mundo se multiplicaron, intensificándose en el siglo XVIII debido al agotamiento del cinabrio en las minas de Huancavélica (Perú).

Salvo excepciones, como el mercurio en Almadén, la mayor parte de los complejos sufren un importante declive a partir del siglo XVII que no es superado hasta el siglo XIX, cuando los avances legales (Ley Minera de 1825 y Bases Generales para la Legislación Minera de 1869) favorecen la entrada de capitales extranjeros que ofrecen nuevos bríos a esta actividad, beneficiada más tarde por la llegada del ferrocarril. Como ejemplo, en 1844, se habían denunciado 28 minas de plomo, 2 de plomo argentífero, 2 de hierro y 6 escoriales de plomo en esta zona (Quirós, 1969: 512). Así, el último tercio del siglo XIX coincide no sólo con la reactivación de la minería de la plata y el plomo, con la explotación de nuevos complejos minero en el Valle de Alcudia y Sierra Madrona (Minas del Horcajo) sino con el descubrimiento de la cuenca minera de Puertollano (1873). En ella las empresas francesas y belgas fueron vitales para su desarrollo, alcanzando su mayor auge en el período correspondiente a la I Guerra Mundial en el que junto a la hulla se comienza a extraer otro mineral, las pizarras bituminosas.

Pero, junto a las extracciones mineras basadas en la abundancia de materias primas minerales en este territorio, la transformación de algunas de ellas dio paso a la industria. Ésta ha experimentado una evolución siempre pareja a la propia minería. El caso más claro lo encontramos en la modernización y mecanizaciones en las labores de destilado del cinabrio en Almadén, materializadas en las xabecas para azogue que introdujeron los árabes a modo de hornos rectangulares cerrados por bóvedas de medio punto en los que calentaba el cinabrio para la obtención de mercurio; y, más tarde, en los hornos de reverberación o buitrones como exponentes de la metalurgia del cinabrio que tradicionalmente se incluye en las labores mine- 
ras pero que implica un proceso industrial, sustituidos, más adelante por las horcas de aludeles. Sin embargo, son las actividades desarrolladas en el área de Puertollano las que presentan una diferenciación más clara, sobre todo en cuanto a legado patrimonial se refiere. Como ejemplo, por sus fundiciones (Ntra. Sra. de Gracia, 1882; La Paz, 1886) pasaban la mayor parte de galenas de la provincia (Quirós, 1969: 589-590) y se encuentran en el origen de la industrialización, junto con el tratamiento de las pizarras bituminosas para la obtención de aceites industriales que la Sociedad Minero-Metalúrgica de Peñarroya había iniciado en 1917. Dicho desarrollo industrial se aceleraría durante la posguerra, siendo el responsable de la evolución económica y social de este núcleo después de la creación, por el Instituto Nacional de Industria, de la Empresa Nacional «Calvo Sotelo» con el objetivo de destilar las pizarras a gran escala durante la Autarquía. Posteriormente estas actividades se reorientarían hacia la petroquímica, manteniéndose la minería del carbón hasta la actualidad.

\subsection{El patrimonio heredado. Análisis y tipología}

Cuando se revisa el patrimonio heredado de carácter industrial la variedad de situaciones es enorme, aunque a la cabeza se encuentran aquellos territorios industriales, o mineroindustriales que, como en este caso, están en declive y buscan una alternativa económica para el futuro, lejos de las actividades secundarias. Los elementos materiales, derivados aquí de una minería con más de 2.500 años de antigüedad, son muestra inequívoca de un «paisaje construido, cultural e histórico» (Campesino, 1998) que es, en realidad, el propio territorio y se relacionan, fundamentalmente, con explotaciones abandonadas, castilletes, lavaderos, hornos, maquinaria y edificaciones en el caso de la minería, así como restos fabriles, edificaciones, maquinaria industrial y utillaje en el caso de la industria. Dichos elementos, muchas veces minusvalorados, son imprescindibles para conocer las relaciones de un determinado grupo social con el espacio que habitan o han habitado. En definitiva, son imprescindibles para saber «el modo en que una sociedad se acomoda, a través de equilibrios mas o menos frágiles, más o menos estables, más o menos adaptados a la diversidad de circunstancias naturales, en orden a su explotación y su propia supervivencia» (Ortega, 1998: 43). A continuación nos detendremos en los elementos más representativos que encontramos en cada una de las áreas anteriormente citadas.

\subsubsection{La Comarca de Almadén}

Las peculiares características de la explotación del cinabrio con tan larga tradición, nos han dejado un importante legado patrimonial que está relacionado no solo con la producción de mercurio sino con la formación de los mineros y su modo de vida, reflejado en los restos edificatorios del reinado de los Borbones Ilustrados. Esta es la razón por la que «las ciudades de Almadén y Almadenejos forman un importante conjunto de arquitectura industrial, tanto de la derivada de la tecnología minera, como de la actividad social con ella relacionada» (Peris, 1995: 115).

Comenzando por los elementos vinculados a la extracción de cinabrio y su transformación en mercurio, cabe resaltarlos como los más valiosos de esta zona tanto por su antigüedad como por la importancia que presenta su conservación como testimonio de la economía minera. Sobresalen, en primer lugar, los Hornos Bustamante, hornos de aludeles que reciben su nombre de Juan Alonso de Bustamante quien los introdujo en estas explotaciones en 1646. Hasta ese momento se habían utilizado las xabecas árabes y más adelante los hornos 
de reverberación o de buitrones. Los hornos bustamante, ideados por Lope Saavedra Barca hacia 1643, fueron aplicados en las minas sudamericanas de Huancavélica (Perú) y se utilizaron en Almadén hasta principios del siglo XX, siendo complementados con otros más avanzados como los de Idria (introducidos en 1806), los Livermoor (1887) y los Spirek (1902). Básicamente, estas instalaciones de mampostería ordinaria y verdugadas de ladrillo, se componen de una pareja de hornos de destilación que se sirven mutuamente de abrigo, un hogar cilíndrico rematado por una semiesfera en el que ubicaban la caldera y la chimenea, así como diversos caños de barro o muelas que conducían los humos, gases y el vapor de azogue, en la parte superior. Allí se encontraban un plano inclinado descendente (plan de cabecera) y uno ascendente (plan de rabena) sobre los que se disponían 24 filas de aludeles en forma de cañerías paralelas (Herce y Otros, 1998: 134). Funcionaron entre 1720 y 1928 , experimentando diversas mejoras y denotando una gran calidad constructiva. De todos los existentes se conserva una pareja en buen estado, localizada en las explotaciones de Mayasa (Minas de Almadén y Arrayanes) y con expediente de Bien de Interés Cultural (B.I.C.) incoado desde el 27 de mayo de 1983 (Fotografía 1). En estado semiruinoso encontramos los restos de cinco parejas más en Almadenejos, correspondientes a la Mina Nueva Concepción. En conjunto, constituyeron «un hito de la metalurgia del cinabrio en Almadén, y por tanto en el mundo, con una trayectoria impresionante en el tiempo, que les confiere un alto valor histórico y técnico» (Peris, 1995: 119).

Por su parte, los Bariteles eran edificios circulares que albergaban el malacate (baritel) que, accionado por caballerías, practicaba las tareas de extracción y desagüe de los pozos. Estas máquinas constaban de un árbol vertical provisto de una o varias palancas horizontales, en cuyo extremo se enganchaban las caballerizas que daban vueltas en torno al árbol. Surgen como evolución de los tornos de extracción a mano y el aumento de profundidad en los pozos. Se utilizaron desde mediados del siglo XVIII hasta la instalación de los castilletes metálicos a finales del siglo XIX y la introducción de la máquina de vapor. Actualmente, se conservan dos: el del Pozo San Andrés en el primer piso de la Mina del Castillo y el del Pozo de San Carlos en la Mina Nueva Concepción de Almadenejos que data de finales del siglo XVIII y tiene incoado expediente de B. I. C. de fecha 19 de septiembre de 1985 (Fotografía 2). Situado en el exterior, consta de una sola pieza de planta circular (con 17 metros de diámetro) y poligonal (16 lados), se remata en el interior con una bóveda esférico-cónica y al exterior con cubierta de teja cerámica curva a 16 aguas y está realizado en fábrica vista con mampostería ordinaria y verdugadas de ladrillo.

Como evolución de los bariteles se construyeron castilletes metálicos. Aún se conserva el Castillete del Pozo San Aquilino, único de estas características que corresponde a una de las innovaciones que tienen lugar en el Cerco de San Teodoro a partir del siglo XIX y mantiene su Sala de Máquinas con parte de la maquinaria. Por su parte, los Cercos delimitaban superficies amuralladas en las que se llevaba a cabo la explotación minera y hoy se conservan sólo parcialmente. Destacan el citado Cerco de San Teodoro, el Cerco de Buitrones o de Destilación que alberga la pareja de Hornos Bustamante, el almacén de azogue y otros edificios industriales, y donde encontramos la Puerta de Carlos IV (1786) realizada en ladrillo y con características neoclásicas con escudo en el frontón que remata en una cruz; y el Cerco de la Mina del Pozo, hoy casi totalmente arrasado. En Almadenejos el Cerco, denominado también de Buitrones, conserva gran parte de la muralla (1755-1757) y algunos restos de los hornos.

Respecto a las edificaciones vinculadas a la producción y cultura minero-industrial de esta comarca destaca, en primer lugar, la Casa Academia de Minas (1777), primera de España en la formación de ingenieros de minas y después convertida en Escuela de Capa- 
taces. Se trata de un edificio noble y de sólida fábrica en el que prima la fachada neoclásica de dos plantas y con aparejos en rústica. En el casco urbano encontramos, también, el Real Hospital de Mineros de San Rafael (1765-1775) que es uno de los pocos elementos catalogados como Bien de Interés Cultural. Destaca, sobre todo, su fachada con una portada central en la que domina una sobria ordenación rematada por una espadaña. Coronado y en una hornacina se ubica el Arcángel San Rafael con iconografía rococó. Los laterales son de fábrica común o mampostería de cal y piedra, enfoscado en cemento y cal. La puerta adintelada está rematada con ladrillo rojo (Peris, 1995: 116).

Estas edificaciones y la identificación de todo un grupo social con la actividad minera, tiene su reflejo en el urbanismo y en la aparición de otros edificios como la Plaza de Toros (1753), vinculada desde su origen a la beneficencia minera y también declarada Bien de Interés Cultural. Se crea como lugar de espectáculos para sacar fondos destinados a la construcción del Hospital de Mineros y más tarde, aprovecha para su edificación la mano de obra paralizada debido a un importante incendio ocurrido en las minas (1755). Actualmente, después de una notable rehabilitación, vuelve a albergar corridas de toros y parte de ella se ha convertido en alojamiento rural. A ello se une la Galería de Forzados, también del siglo XVIII (1754) y recientemente restaurada, que procede de una antigua cárcel de forzados que trabajaban en las minas y que, después de recuperar sus celdas y abrirlas al público, se completará con la apertura de la galería que comunica con la mina.

Respecto a la infraestructura museística, en 1988 se creó el Museo Minero Francisco Pablo Holgado ubicado en la Escuela Politécnica (UCLM) con los objetivos de preservar del deterioro la gran cantidad de instrumentos, equipos, planos o herramientas que poseía la Escuela y la zona minera de Almadén; dar respuesta a las necesidades didácticas de este centro; y ofrecer un conocimiento sobre las minas a los ciudadanos (Mansilla, 2000: 476). Hoy alberga una importante colección de minerales y fósiles que tiene sus orígenes en el Gabinete Mineralógico y Paleontológico de la primitiva Academia de Minas de Almadén y ha sido mantenida a partir de importantes donaciones. Desde su creación ha sido objeto de diversas actuaciones de conservación, recuperación y exposición, e incluso está relacionado con la creación de un grupo de investigación multidisciplinar compuesto por geólogos, historiadores e ingenieros, principalmente.

\subsubsection{El Valle de Alcudia y Sierra Madrona}

En esta zona de tránsito entre la Comarca de Almadén, al suroeste, y la de Puertollano, al norte, se ubican diversos complejos mineros de los cuales destacaremos aquellos que conservan los elementos más significativos. En primer lugar, nos referiremos a las explotaciones romanas bajo el control de Sisapo (actualmente la aldea de La Bienvenida en el término municipal de Almodóvar del Campo) cuyos restos encontramos repartidos de forma dispersa en este territorio, correspondiendo la mayor parte a las labores realizadas en el siglo XIX y primera mitad del XX. Es el caso de las explotaciones del Complejo Minero La RomanaVeredillas en el que se incluyen restos correspondientes a diversas minas como La Romana (Almodóvar del Campo) y La Emperatriz (Brazatortas) de las que se conservan parte de los castilletes de mampostería. Por su parte, el Complejo Minero de San Quintín (Cabezarados) se encuentra casi totalmente arrasado, su antiguo poblado minero ha desaparecido y tan sólo se adivinan algunas edificaciones dedicadas a la extracción de plata, entre las que se encuentra un lavadero. Su elemento más representativo es un castillete, construido en obra de fábrica, a base de mampostería y ladrillo visto, que funcionó con poleas en su parte superior y una 


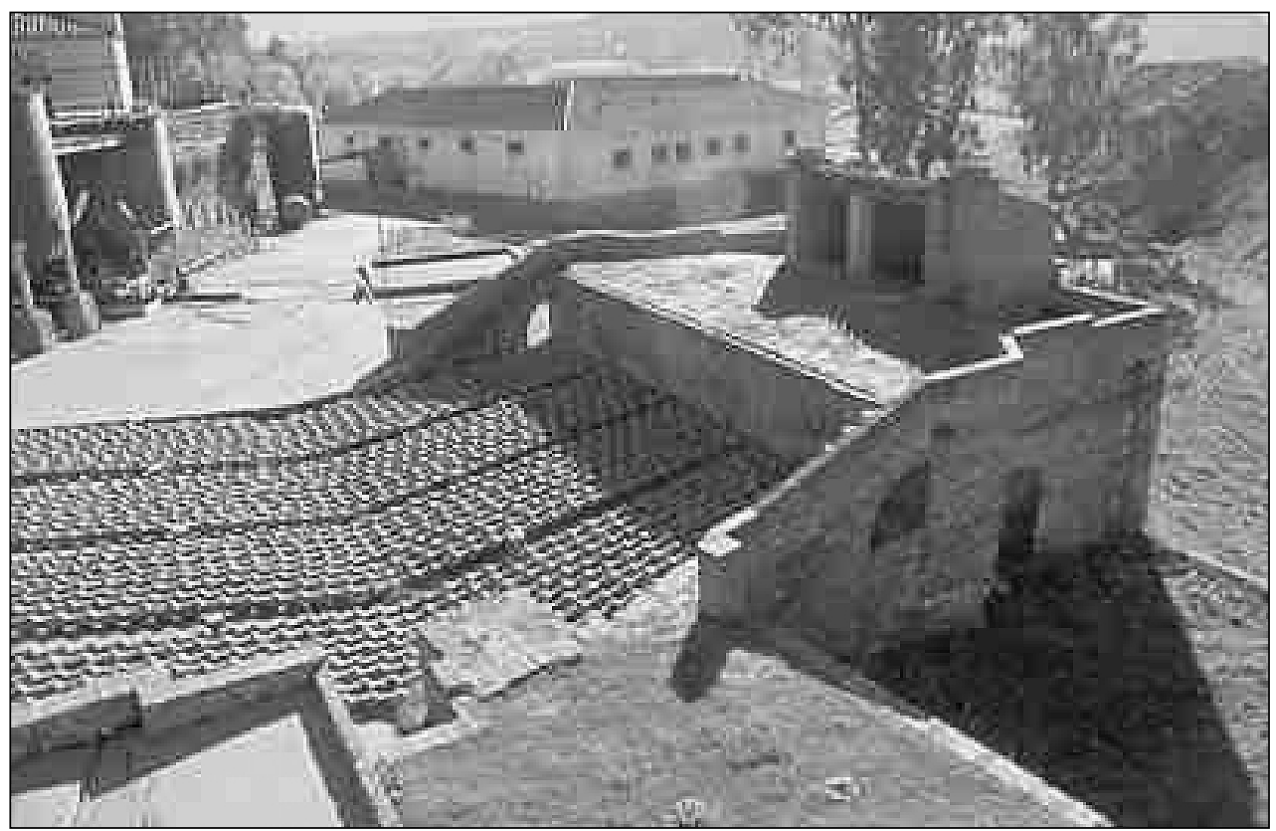

FotogRAFía 1. Hornos Bustamante (S. XVII). Explotaciones de cinabrio (Almadén).

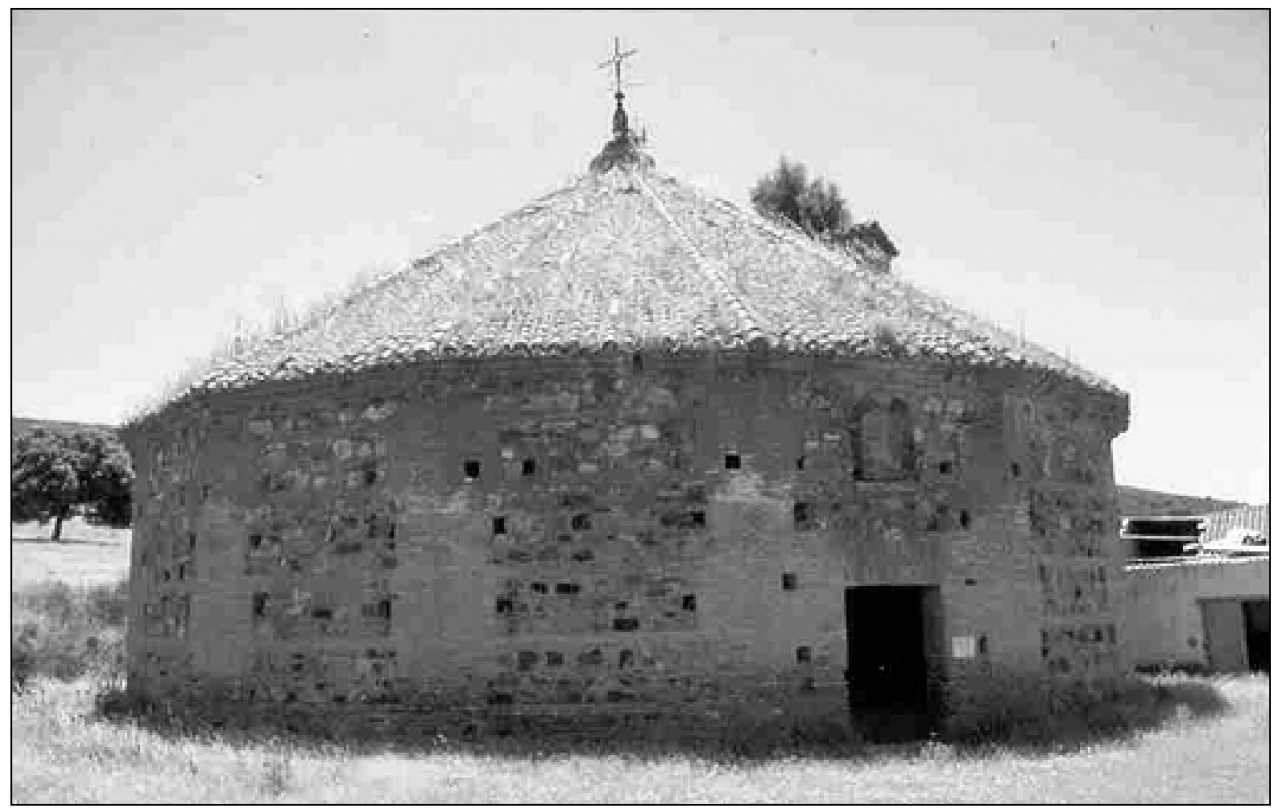

Fotografía 2. Baritel de San Andrés (S. XVIII). Mina Nueva Concepción (Amadenejos). 
sala de máquinas de grandes dimensiones que corresponde al período de mayor auge (18871934) bajo el dominio de la Sociedad Minero-Metalúrgica de Peñarroya (S.M.M.P).

En el caso de la Mina Diógenes, muy relevante durante la romanización pues perteneció al distrito minero de Cástulo (Linares), se conserva, de época contemporánea, el castillete que daba acceso al pozo n. 5, aunque no in situ sino instalado en el patio de la Escuela Politécnica de Almadén. Su torre está compuesta por cuatro planos de perfiles roblonados que soportan un quinto plano sobre el que se apoya la plataforma en la que se ubican las poleas de los cables de extracción (Peris, 1995: 115). Del resto de edificaciones que conformaban este complejo se conserva parte del poblado minero de gran valor por ser representativo del urbanismo obrero francés, así como algunas instalaciones dispersas como lavaderos y talleres en un estado de conservación ruinoso desde su cierre en 1979.

Por su parte y ya de mediados del siglo XIX, el Complejo de Minas del Horcajo experimentó un notable auge entre 1888 y 1910 bajo el dominio de sociedades francesas y belgas que explotaron el plomo y la galena argentífera. Constituye hoy una pequeña aldea de muy pocos vecinos dedicados casi exclusivamente a la ganadería y con una accesibilidad extremadamente dificultosa. Muchos edificios e instalaciones han desaparecido y de los que quedan la mayoría están en ruinas habiendo desaparecido, casi totalmente, el poblado que albergaba viviendas, hospital, farmacia, escuelas, cooperativa de consumo y sociedad recreativa. Encontramos, sin embargo, uno de los castilletes de extracción más interesantes de toda la zona. Construido en obra de fábrica, con estructura de planta cuadrada y de ladrillo macizo. Consta de contrafuertes en cada una de las esquinas y sobresalen dos arcos de medio punto apuntados que, situados en lados opuestos, le confieren gran esbeltez. En los otros dos lados aparecen dos arcos de medio punto encontrados y unidos mediante un vano rectangular. En la parte superior persisten los restos de la estructura de apoyo de las poleas, así como parte del amaine con su plataforma metálica y barandilla quitamiedos (Peris, 1995: 110). También permanece en pie otro castillete, ubicado en el centro de la aldea, que presenta construcción en mampostería y estructura rematada con arcos de medio punto, así como algunos restos de edificaciones relacionadas con las minas.

Puntualmente en esta zona, también cabría destacar algunos castilletes de mampostería como el Pozo Minero Los Dolores (Almodóvar del Campo), restos del Pozo Las Simonas (Hinojosas de Calatrava) y algunos elementos de las minas La Gitana y El Encinarejo (Mestanza), entre otros. Así como también los restos, también en situación de abandono, de antiguas fundiciones romanas como la Fundición de Valderrepisa (Fuencaliente) y la Fundición de El Robledo (San Lorenzo de Calatrava).

\subsubsection{El Área de Puertollano}

Los restos derivados de la minería y de la industria que encontramos en este término municipal son numerosos, convirtiéndola en un «impresionante conjunto de arquitectura industrial» (Peris, 1995: 145). Nos referiremos a aquellos que se datan entre el último cuarto del siglo XIX y la primera mitad del siglo XX, en algunos casos, verdaderos símbolos que han contribuido a revitalizar la imagen urbana de la ciudad (Cañizares, 1999).

En principio, los restos relacionados con la minería del carbón realizada en pozos subterráneos son diversos y se encuentran repartidos por toda la cuenca. Están afectados por dos peligros principales: su estado de abandono y derribo en algunos casos (incluso desguace de piezas y maquinaria) y el avance de la minería a cielo abierto hacia las zonas donde se ubican. El sector más destacado es, sin duda, el Parque del «Pozo Norte». Museo de 
la Minería al Aire Libre, área de ocio y expansión que se creó en 1992 sobre la propia cuenca minera. Coincidiendo con la ubicación de la Mina del Pozo Norte, propiedad de la Sociedad Minero Metalúrgica de Peñarroya, conserva diversos elementos de interés. Especialmente, el Castillete del Pozo Norte (1928) que, localizado en el óvalo superior de la cuenca, es su principal atractivo. Presenta gran esbeltez, alcanzando los $30 \mathrm{~m}$. de altura, y es uno de los mejor conservados. Consta de una estructura de once cuerpos estando abalconado el superior y se culmina con una cubierta a cuatro aguas. La estructura principal es soportada por cuatro grandes pilastras, fortificadas mediante tirantas cruzadas. La sala de máquinas, una de las más avanzadas tecnológicamente se destruyó en 1978, dejando vista la polea que está compuesta por dos bovinas que se encargaban de enrollar el cableado movidas por un motor eléctrico y es el único elemento que se conserva. Lamentablemente, las tolvas, de hormigón armado, se destruyeron para, curiosamente, dejarlo visible.

Expone, también, al aire libre numerosos restos de la minería subterránea, destacando algunas máquinas utilizadas en la extracción de carbón y pizarras. Sobresale la máquina de vapor 050 que fue fabricada en Bélgica hacia 1907, consta de cinco ejes acoplados y pesa 90 Tm., razón por la que era conocida como «La Gorda» (Fotografía 3). También, la máquina 4000-015 (tractor diesel) que realizó labores de extracción, desde 1945, en los Pozos Este, Calvo Sotelo y Plano Inclinado. Por último destaca la máquina tractora de galería (diesel), una de las que suplieron el trabajo de las caballerías en el arrastre de las vagonetas procedentes de la mina, introducida en los años 40. Aparecen, también, otros elementos como vagonetas, chasis de maquinaria, motores o elementos de los scrappers. En la actualidad se está desarrollando un proyecto de ampliación de lo existente a partir de financiación europea (Fondos Feder) y del Ministerio de Industria y Energía que se concreta en la creación de una galería subterránea (Mina-Imagen) y en la rehabilitación de lo que queda de la sala de máquinas del Pozo Norte para sala de exposición, permitiendo la contemplación de los tambores de las poleas. Está proyectada, también, la creación de un Centro de Interpretación de la Minería reacondicionando el Pozo La Cruz, castillete paralelepípedo de mampostería que se sitúa encima de una plataforma y a él se adosa una estructura con bóveda de cañón que albergaba maquinaria. Igualmente, se incluyen actuaciones de tratamiento medioambiental del entorno e integración de los Pozos San Julián y San Felipe, rehabilitando sus castilletes e instalaciones anexas, de modo que quedasen unidas las áreas correspondientes a la Mina Norte y a la Mina San Esteban, a la que ambos pertenecían. El primero consta de cuatro cuerpos, localizándose las poleas en el superior del cual ha desaparecido la cubierta a dos aguas y sus dos jaulas sencillas. Su sala de máquinas, de ladrillo enlucido y tejado a dos aguas, se conserva en situación ruinosa y ha desaparecido la maquinaria. Quedan unos lavaderos y una chimenea que, probablemente, pertenecería a un horno de fundición. Por su parte, el Pozo San Felipe conserva, básicamente, el castillete con estructura metálica de cinco cuerpos, presentando una mezcla entre castillete y cabestrante, y la sala de máquinas de ladrillo enlucido con cemento y cubierta a dos aguas, donde aún permanecen las bovinas y el cableado de elevación de las jaulas ya desaparecidas.

Entre los castilletes metálicos, fuera de la cuenca minera encontramos el Castillete del Pozo Santa María que perteneció a uno de los complejos mineros más importantes con urbanización anexa, Asdrúbal, hoy desaparecido. Consta de siete cuerpos rematados con estructura abalconada y cubierta a cuatro aguas. La estructura central es de cuatro pilares unidos entre sí mediante vigas. Se remata con escalera metálica permitiendo el acceso al cuerpo superior donde se encuentran las poleas. Los contrafuertes se componen a partir de dos grandes pilastras realizadas a partir de vigas paralelas. Hoy se encuentra exento y, des- 
pués de ser rehabilitado, se ha reubicado en la entrada norte de la ciudad de Puertollano para protegerlo del avance de la minería a cielo abierto.

Por su parte, diversos castilletes aparecen dispersos en la antigua cuenca como el Castillete del Pozo Elorza que se ubica en la zona noroeste del óvalo inferior de la cuenca, actualmente explotada por la empresa Encasur S.A., que lo utiliza para extraer agua de sus galerías. Consta de siete cuerpos y su estructura central está formada por cuatro pilastras simples de dos vigas paralelas. El cuerpo superior, abalconado y con dos poleas paralelas, se remata con un tejado de chapa abovedado. La sala de máquinas no se conserva y lo que encontramos es el taller de selección a modo de gran edificación rectangular que se adosa al frente del castillete y descansa sobre una gran estructura de hormigón rematada por arcos de medio punto. Mantiene íntegra la estructura de apoyo de la instalación de tratamiento y ensilado, construida en obra de fábrica y que conserva una interesante bóveda por la que accedían los vehículos debajo de las tolvas para su carga (Peris, 1995). Adosados aparecen un depósito de agua metálico y la tolva cilíndrica unida al mecanismo de volteo de las vagonetas. Finalmente, el Castillete del Pozo Arguelles, ubicado en la zona central del óvalo sur, constituye, en realidad, un cabestrante perteneciente a uno de los complejos de cuyas edificaciones tan solo se adivinan los cimientos.

Muy relevantes son, también, los castilletes de mampostería y las edificaciones anexas aunque, en general, están peor conservados que los de estructura metálica, como también sucede con otros vinculados a la minería de plomo y plata en el Valle de Alcudia. Destaca, en primer lugar, el Pozo Don Rodrigo, que está reforzado con vigas de madera. Consta de una estructura central, contrafuertes de ladrillo oradados con arcos de medio punto y rematados por hiladas de ladrillo junto a los que se conserva, también, un pequeño aljibe, formado por muros de ladrillo que ha sido utilizado como almacén y unos anexos que podrían corresponder al taller de selección. También, el Pozo Valdepeñas reproduce en mampostería la estructura de los castilletes metálicos con zona central para las jaulas y contrafuertes con arcos de medio punto de ladrillo, hoy tapiados.

Los elementos vinculados a la industrialización son también numerosos en Puertollano. Sobresalen los que encontramos en uno de los primeros complejos industriales españoles, hoy conocido como Apartadero Calatrava y absolutamente infravalorado (Cañizares, 2002). En él se ubicó la subestación de ferrocarril en la que se acumulaba el carbón para ser transportado. Hoy conserva los restos de edificios y maquinaria derivada de las instalaciones fabriles que la Sociedad Minero-Metalúrgica de Peñarroya dirigió en las inmediaciones de la cuenca minera, donde desarrollo el proceso industrial de destilación de pizarras y producción de energía termoeléctrica. Entre los elementos más destacables encontramos la Central Termoeléctrica que data de 1917 y es el edificio más importante de los que se conservan (Fotografía 4). Hoy permanecen el edificio central, diáfano de dos alturas con aparejo de ladrillo rojo y rematado con cubierta a dos aguas y grandes cristaleras, y las torres de refrigeración, construidas a partir de grandes cilindros de hormigón elevados en pilares. Importante es, también, la Destilería de Pizarras Bituminosas que, con carácter experimental, se instaló en las inmediaciones de la central termoeléctrica. Incorporaba un circuito principal de destilación, condensación de vapores de aceites, recuperación de esencias y grasa así como otras instalaciones complementarias. Junto a estos edificios, también ruinosos, se conservan las chimeneas, también de ladrillo, correspondientes a los hornos. En las inmediaciones se ubicaba el Taller Central, edificio adosado a las vías del tren que comienza a funcionar en 1919 para la reparación de la maquinaria así como el Taller de Reparación de Maquinaria del Ferrocarril Minero, uno de los edificios más grandes al que accedían las máquinas de vapor que circula- 
ban en la cuenca. Lamentablemente estos claros exponentes de la arquitectura industrial de principios de siglo han sido desvalijados para vender la maquinaria como chatarra sin que se haya hecho nada por evitarlo. Su actual propietario, la empresa Cerconsa S.A., mantiene en situación de ruina no solo las edificaciones sino otros restos con valor patrimonial como vagonetas mineras, repartidas a la intemperie y en estado precario.

Para finalizar, cabe citar que en la zona urbana, también se conservan algunas edificaciones relacionadas con la minería y la industria, como el Museo Municipal localizado en la antigua Casa Consistorial (1923) y que alberga, desde 1996, dos salas de exposición permanente sobre útiles y aparejos mineros con ejemplos del material existente en la cuenca (vagonetas, linternas, etc.) así como una revisión cartográfica de las características geológicas del territorio correspondiente a estas explotaciones.

\section{Perspectivas futuras}

Partiendo de que la conservación y valoración del patrimonio minero-industrial ha adquirido gran interés en los últimos años, es muy importante saber qué hacer con estos restos del proceso industrializador que, funcionalmente obsoletos en la mayor parte de los casos, poseen valores técnicos y arquitectónicos indiscutibles así como simbólicos al formar parte de la memoria colectiva de la población. En esta zona de la provincia de Ciudad Real, como en otras de Castilla-La Mancha, de nuestro país y del exterior «ha debido desaparecer buena parte de ese tejido industrial para que los ciudadanos tomaran conciencia de que con esas vetustas instalaciones se perdía un trozo de historia económica nacional, y también de la actividad humana que dio su forma actual a las ciudades» (Francescutti, 1993: 92). Ello no impide, sin embargo, que se pueda valorar correctamente lo que se ha salvado a través del tiempo, tanto en su dimensión tecnológica (arquitectura y tecnología de la construcción) como social (modos de vida).

Una vez definidos claramente los criterios de conservación, aún inexistentes pues no existe un catálogo específico de tipo industrial, la posible reutilización aparece en el momento en que han dejado de ser viables económicamente como en este caso. Se proponen, entonces, múltiples usos generalmente relacionados con el sector terciario, tales como los servicios comerciales, edificios institucionales, instalaciones culturales, zonas de ocio o áreas de turismo cultural. En el caso concreto que ahora analizamos se plantean diferentes razones para justificar la protección, conservación y la posible utilización futura. Nos referimos a razones de carácter monumental, histórico y cultural. En el caso de las primeras aún queda mucho camino por recorrer, puesto que, a pesar del reconocimiento de valores histórico-artísticos o monumentales hacia muchos de estos elementos, sólo en dos casos están catalogados como bienes de interés cultural (el Real Hospital de San Rafael y a la Plaza de Toros de Almadén), aspecto que, indirectamente, dificulta la protección de los demás. En relación con las razones históricas y culturales, queda claro que los casos antes comentados componen la memoria histórica identificada con un territorio concreto. No solo el mantenimiento de instalaciones que permiten estudiar procesos productivos ya obsoletos es importante sino el hecho de que «los ciudadanos de esas sociedades pueden perder la conciencia de lo que fue el pasado» (Capel, 1996: 36).

Sin duda, su consideración como recursos, en una doble vertiente (culturales y económicos) así como su integración en las estrategias de desarrollo local se presentan como los fines principales a los que se pueden dedicar estas instalaciones convenientemente rehabilitadas, lo cual aseguraría su reutilización y revalorización. Son numerosas las propuestas en este sentido, algunas de ellas en funcionamiento desde los años 70, que se concretan en 
Museos Integrales, Parques Culturales o de Ecomuseos se reparten por Europa y España, en los cuales se valoriza el patrimonio a la vez que se protege, destacando un elemento clave: la «territorialidad», entendida como «vinculación del hombre a una realidad cultural y social concreta» (Troitiño, 1998: 101-102).

En el territorio que hemos delimitado el futuro se presenta incierto, aunque la presencia de diferentes líneas de financiación parece aportar algo de esperanza. Nos referios a programas de desarrollo rural como el Proder «Montesur» en la Comarca de Almadén, a iniciativas como el Leader Plus «Valle de Alcudia-Sierra Madrona» en el área del mismo nombre, y a los Fondos del Ministerio de Industria y Energía para la reconversión de las comarcas mineras en la zona de Puertollano. Además algunos complejos minero-industriales de este territorio delimitado han sido escogidos dentro del Plan de Patrimonio Industrial que el Instituto del Patrimonio Histórico Español ha iniciado en el año 2000. Concretamente, nos referimos a la zona minera de Almadén y la zona minera de Puertollano, enclaves a los que se unen, en Castilla-La Mancha, la Real Fábrica de Metales de Riópar en San Juan de Alcaraz (Albacete) y la Real Fábrica de Paños de Brihuega (Guadalajara) sobre los que también se plantean diversas actuaciones.

En relación con este plan Minas de Almadén y Arrayanes S.A. (Ministerio de Industria) propietaria de las minas en la Comarca de Almadén, ha iniciado un Plan Director para la recuperación del patrimonio de Mayasa en Almadén y su conversión en espacio sociocultural (2002) con el fin de paliar el declive que supone la falta de viabilidad económica en las explotaciones. Basado en un planteamiento ecomuseístico en el que el patrimonio permanece en su localización original, incluye tanto los restos materiales como las edificaciones y las propias minas y propone la creación de un Parque Minero en el Cerco de San Teodoro o Buitrones (Almadén), donde actualmente se ubica un pequeño museo minero que recoge muestras históricas de la minería del mercurio y objetos industriales. Su finalidad es mostrar al visitante los procesos minero-metalúrgicos asociados a la producción de mercurio con recorridos al interior de la explotación. Para ello contempla la restauración ambiental del entorno y la revitalización urbanística del área cercana a las instalaciones, así como la rehabilitación del Real Hospital de San Rafael para albergar el citado Archivo Histórico de Mayasa, el Museo Hospitalario Minero y la Sede de la Fundación Francisco Villegas.

En el caso del Valle de Alcudia y Sierra Madrona se está procediendo al inventario y catalogación de los elementos existentes para su complemento con otros recursos estratégicos de la zona como las cañadas o las pinturas esquemáticas del Arco Mediterráneo. Y finalmente, en Puertollano, con la ampliación del Museo de la Minería al Aire Libre se pretende consolidar un uso turístico, en primer lugar, y resaltar su vertiente didáctica para que generaciones futuras puedan acercarse con facilidad al pasado de su ciudad, consolidándose como una apuesta de desarrollo endógeno (Cañizares, 2001b). Las previsiones respecto al aprovechamiento turístico de esta zona apuntan unos 30.000 visitantes el primer año, teniendo en cuenta que «se incrementará considerablemente (...) al contar con una población de más de cien mil habitantes comarcales, doscientos cincuenta mil provinciales y con un potencial de turismo nacional de gran magnitud al encontrarse la localidad unida por AVE con Madrid, Ciudad Real, Córdoba y Sevilla» (A.P., 2000). Aspectos ya analizados (Cañizares, 2001a).

De forma conjunta hemos identificado un territorio minero correspondiente a lo que los geólogos denominan el Distrito Minero de Valle de Alcudia y el Distrito Minero de Almadén. Un territorio con un largo pasado en la minería y en la industria y un gran potencial territorial para la puesta en valor y correcto aprovechamiento de su legado patrimonial. Como hemos analizado, presenta diversas singularidades ya que «una mina es diferente 


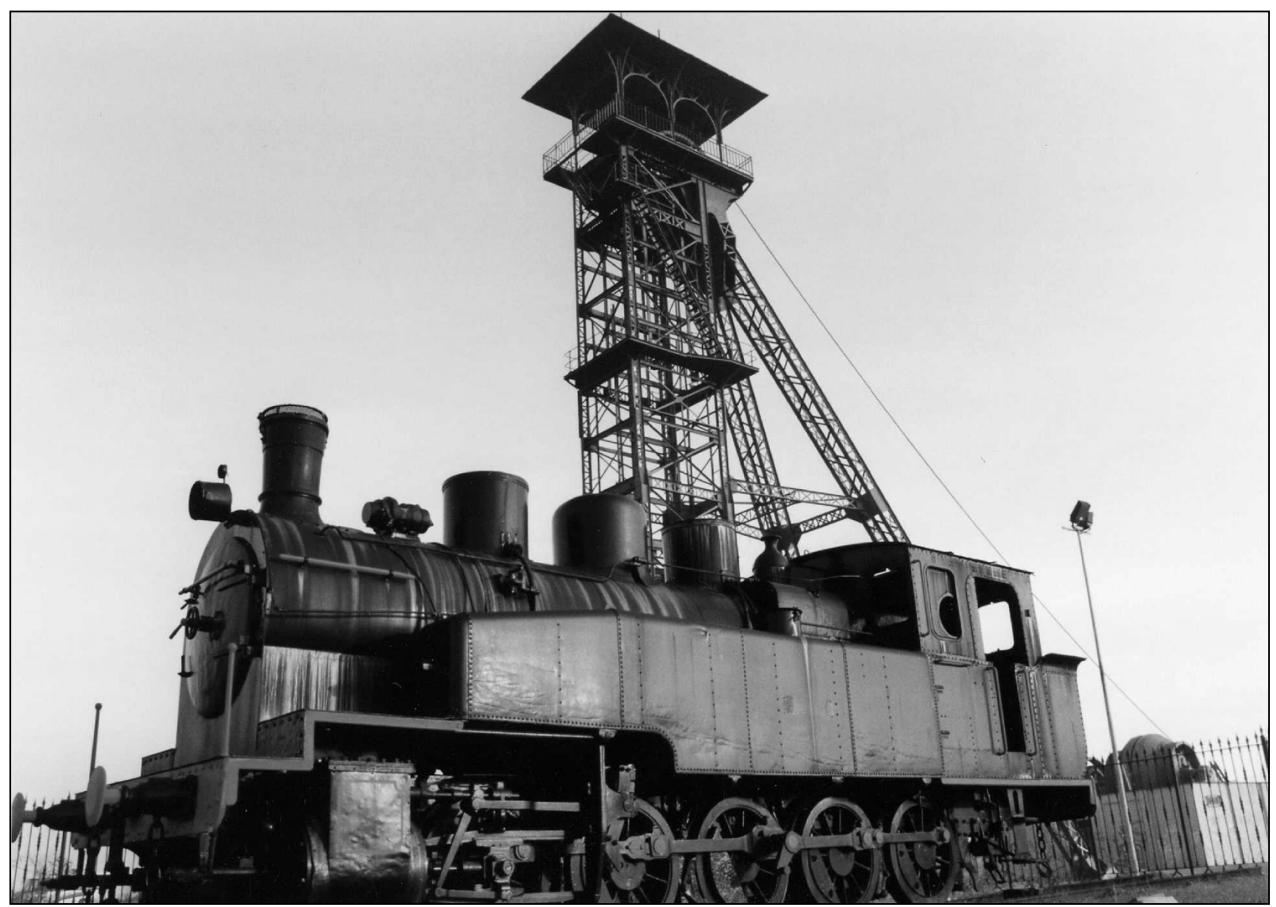

Fotografía 3. Museo de la Minería al Aire Libre. Pozo Norte y «La Gorda» (Puertollano).

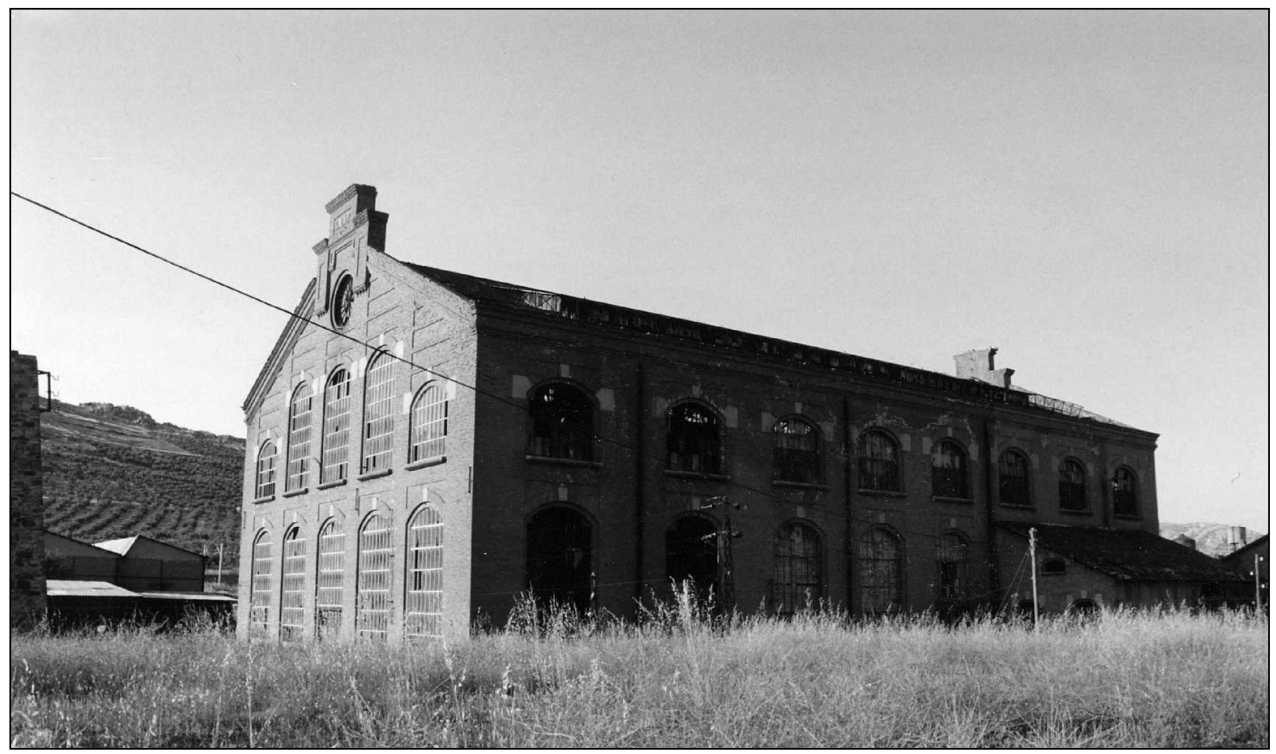

Fotografía 4. Apartadero Calatrava. Central Termoeléctrica (Puertollano). 
según el tipo de explotación que se realice, pero también lo es por el ecosistema donde está situada, por la organización social que se implanta en torno a ella y por su historia» (Casanelles, 1998: 15-16), y son estas diferencias las que la convierten en un espacio único en el mundo. Singularidad que debe ser incorporada a las políticas de desarrollo.

En este sentido y para concluir es necesario señalar una carencia importante y fundamental en los casos analizados. Es el hecho de que aún no se han valorado estos recursos en favor del desarrollo local. Dado el potencial que conservan es difícil entender que aún no se hayan incorporado como elementos activos en las estrategias de desarrollo, ya que el objetivo debe ser «dinamizar social y económicamente una zona deprimida, recuperar actividad y empleo allí donde el cierre de minas y fabricas amenaza con la desertización humana y la degradación física del espacio» (Benito del Pozo, 1998: 172). Consideramos que el patrimonio debe cumplir aquí la función de ser un elemento revitalizador de las economías regionales y locales bajo modalidades que abarcan desde la conservación y exhibición de los restos de la industrialización, hasta la rehabilitación de edificios y terrenos para nuevas actividades empresariales o para proyectos de turismo cultural y turismo de naturaleza, sin olvidar las operaciones de limpieza ambiental y urbanística de ciudades degradadas por la industria (Benito del Pozo, 1998: 177).

Sería deseable, también, una mayor sensibilización de la opinión pública ante la ausencia de presión en favor de la protección, puesto que también podríamos hablar de este patrimonio en términos de una «apasionante necesidad social» (Puche y Manzadiego, 1999: 43). La ausencia de legislación específica y de adecuados modelos de gestión territorial nos deja a expensas del deber constitucional que los poderes públicos tienen de garantizar la conservación y promover el enriquecimiento del patrimonio histórico, haciendo referencia a todos los bienes que tienen valor cultural, algo que es, a todas luces, insuficiente. Afortunadamente en un futuro inmediato las actuaciones previstas podrán «rescatar» algunos de estos elementos y ponerlos convenientemente en valor para el disfrute de la población y la mejora económica de los territorios en los que se encuentran. Otros, con seguridad, se perderán, sin haber gozado de la correcta valoración que requieren.

\section{Bibliografía}

ACOSTA, A. (1998) (Coord.): El Valle de Alcudia. Naturaleza y Patrimonio Cultural. Biblioteca de Autores Manchegos. Ciudad Real.

ALONSO IBÁÑNZ, M. R. (1992): «El régimen jurídico de la Arqueología Industrial», en Ábaco, n. 1 (2 época) primavera, Oviedo, pp. 67-70.

AYUNTAMIENTO DE PUERTOLLANO (1995): Elementos Mineros conservados en la Cuenca de Puertollano, Vol. I y II, rústica, Puertollano.

AYUNTAMIENTO DE PUERTOLLANO (1999): Museo de la Minería del Pozo Norte, Puertollano. Ciudad Real, Puertollano (rústica).

AYUNTAMIENTO DE PUERTOLLANO (2000): Programa Operativo Local (POL). Proyecto: Museo de la Minería al Aire Libre, documento, Puertollano.

BENITO DEL POZO, C. (1996): «Europa ante el Patrimonio Industrial», en Revista Asturiana de Economía, n. 6, Oviedo, pp. 183-195.

BENITO DEL POZO, P. (1998): «Patrimonio Industrial y cultura del territorio», en Ciudades, n. 4 (monográfico Territorio y Patrimonio), Valladolid, pp. 171-178.

BENITO DEL POZO, P. (2002): «Patrimonio Industrial y estrategias de desarrollo», en Boletín de la Asociación de Geógrafos Españoles, n. 34 (2ºmestre), Murcia, pp. 213-217. 
CAMPESINO FERNÁNDEZ, A. J. (1998): «Territorio y Patrimonio Cultural. El paisaje de frontera», en Encuentro Transfronterizo sobre Patrimonio en la Raya, ADESVAL (Asociación para el Desarrollo del Valle del Alagón), Coria (inédito), 25 pp.

CAÑIZARES RUIZ, M. C. (1999): «Los símbolos mineros como elementos revitalizadores de la imagen urbana en la ciudad de Puertollano (Ciudad Real)», en VV. AA. El territorio y su imagen, Vol. II, AGE y Universidad de Málaga, Málaga, pp. 977-986.

CAÑIZARES RUIZ, M. C. (2001a): «Potencialidades turísticas del patrimonio territorial en Puertollano y su Comarca», en Campo de Calatrava. Revista de estudios de Puertollano y su comarca n. 4, Puertollano, pp. 9-38.

CAÑIZARES RUIZ, M. C. (2001b): «El Museo de la Minería en Puertollano (Ciudad Real). Una apuesta de desarrollo endógeno», en Actas del XVII Congreso de Geógrafos Españoles, Oviedo, pp. 272-275.

CAÑIZARES RUIZ, M. C. (2002): «La infravaloración del patrimonio industrial urbano. El «Apartadero Calatrava» en Puertollano (Ciudad Real)», en FERNÁNDEZ, F., PUMARES, P. y ASENSIO, A. (Eds.) Turismo y transformaciones urbanas en el siglo XXI, A. G. E. y Universidad de Almería, Almería, pp. 493-504.

CAPEL, H. (1996): «La rehabilitación y el uso del Patrimonio Histórico Industrial», en Documents d'Análisis Geographica, n. 29, Barcelona, pp. 19-50.

CARRERA SÁNCHEZ, M. C. (1986): «Estructura y dinamismo de la industria en CastillaLa Mancha: importancia de la industria agroalimentaria», en El Campo, n. 102, Bilbao, pp. 124-138.

CASANELLES, E. (1998): «Recuperación y uso del patrimonio industrial», en Ábaco, n. 19 ( $2^{a}$ época), Oviedo, pp. 11-18.

CASANELLES, E. (2001): «El patrimonio industrial», en ÁLVAREZ, M. A. (Coord.) Arqueología Industrial. Patrimonio y Turismo Cultural, INCUNA, Gijón, pp. 33-40.

CEDER Valle de Alcudia-Sierra Madrona (2000): «El territorio ordenado», en Actualidad Leader n. 11 (septiembre), Madrid, pp. 34-35.

COMISIÓN EUROPEA (1999): ETE. Estrategia Territorial Europea. Oficina de Publicaciones de las Comunidades Europeas. Luxemburgo.

FERNÁNDEZ, M.F. (2003): La Casa Academia de Minas, 225 años de su fundación. Almadén, 2002. Escuela Universitaria Politécnica de Almadén, Colegio Oficial de Ingenieros Técnicos de Minas de Almadén y Diputación de Ciudad Real, Ciudad Real.

FRANCESCUTTI, P. (1993): «Recuperación de edificios industriales. Tesoros fabriles», en Revista MOPT, n. 409 (mayo), Madrid, pp. 91-95.

GARCÍA GARCÍA, G. (1998): «La adaptación de la Mina Alfredo (Riotinto) para visitas», en Ingeopres (Actualidad Técnica de Ingeniería Civil, Minería, Geología y Medio Ambiente), n. 58 (marzo), Madrid, pp. 56-60.

GARCÍA RAYEGO, J. L. (1997): «Introducción. El medio natural y sus unidades en el sur de la meseta meridional», en GARCÍA, J. L. y GONZÁLEZ, E. (Coords.) Elementos del medio natural en la provincia de Ciudad Real, Servicio de Publicaciones de la Universidad de Castilla-La Mancha, Cuenca, pp. 11-19.

GARCÍA RAYEGO, J. L. (1999): «El Medio Natural», en GARCÍA CANSECO, J. (Ed.) El Valle de Alcudia, Ed. Esfagnos S. A., Madrid, pp. 11-21.

GÓMEZ VOZMEDIANO, M. F. (2000): «La minería en el Valle de Alcudia y sus aledaños durante el antiguo régimen (1250-1860)», en Campo de Calatrava. Revista de Estudios de Puertollano y su comarca, Puertollano, pp. 77-189. 
HERCE, J. A. y OTROS (1998): Apuntes sobre Arquitectura Industrial y Ferroviaria en Castilla-La Mancha 1850-1936. Colegio Oficial de Arquitectos. Guadalajara.

IPH (Instituto del Patrimonio Histórico) (2000): Plan de Patrimonio Industrial. Madrid.

MANSILLA, L. (2000): «Anteproyecto museográfico del Museo Histórico-Minero «Francisco Pablo Holgado» (Almadén, Ciudad Real)», en RÁBANO, I. (Ed.) Patrimonio Geológico y Minero en el marco del Desarrollo Sostenible, IGM, Madrid, pp. 475-482.

MÉNDEZ, R. (2001): «Modelos de industrialización en Castilla-La Mancha: innovación para el Desarrollo Local» en PILLET, F. y PLAZA, J. (Coords.) Lecciones de Desarrollo Rural. Una aproximación formativa desde y para Castilla-La Mancha, UCLM y CEDERCAM, Ciudad Real, pp. 213-217.

MÉNDEZ, R. y CARRERA, C. (1999): «Localización de las industrias», en TAMAMES, R. y HERAS, R. (Dirs.) Enciclopedia de Castilla-La Mancha, Vol. II Espacio Humano, Edicsa, Madrid, pp. 137-150.

ORTEGA VALCÁRCEL, N. (1998): «El Patrimonio Territorial: el territorio como recurso cultural y económico», en Ciudades, n. 4, Valladolid, pp. 33-48.

PALERO FERNÁNDEZ, F. J. (2000): «Geología de los yacimientos minerales en el distrito minero del Valle de Alcudia (Ciudad Real)», en Campo de Calatrava. Revista de Estudios de Puertollano y su comarca, Puertollano, pp. 17-41.

PANADERO, M. y PILLET, F. (1999): «Castilla-La Mancha», en GARCÍA, J. M. y SOTELO, J. A. (Eds.) La España de las Autonomías, Síntesis, Madrid, pp. 291-330.

PARDO PARDO, M. R. (1996): La industria en Castilla-La Mancha en el período de la recuperación (1985-1991). Civitas y Junta de Comunidades de Castilla-La Mancha. Madrid.

PARDO PARDO, M. R. (Coord.) (2000): Historia económica de Castilla-La Mancha (siglos XVI-XX). Celeste Ediciones. Madrid.

PERIS, D. (Coord.) (1995): Arquitecturas para la Industria en Castilla-La Mancha. Junta de Comunidades de Castilla-La Mancha. Toledo.

PUCHE, O. y MANSILLA, L. (1985): «Almadén, 2. 500 años de extracción del mercurio», en Industria Minera, n. 247 (marzo), Madrid, pp. 25-31.

PUCHE, O. y MANZADIEGO, L. F. (1999): «Conservación del patrimonio minero-metalúrgico español: actuaciones recientes, propuestas y su financiación», en MANSILLA, L. y FERNÁNDEZ, R. C. (Coords.) Actas de la I Reunión Científica sobre Patrimonio Minero Metalúrgico, Universidad de Castilla-La Mancha, Cuenca, pp. 43-53.

QUIRÓS LINARES, F. (1969): «La minería en el Valle de Alcudia y en el Campo de Calatrava», en Estudios Geográficos, n. 117 (noviembre), Madrid, pp. 505-626.

RIERA Y TUEBOLS, S. (1996): «Ciencia, tecnología y Arqueología Industrial», en Ábaco, n. 8 (2 época), Oviedo, pp. 27-36.

SANTACREU, J. M. (1992): «Una visión global de la Arqueología Industrial en Europa. Casos concretos en regiones concretas», en Ábaco, n. 1 (2 época), Oviedo, pp. 13-28.

SUÁREZ-INCLÁN, M. R. (1998): «Patrimonio y urbanismo. Dos universos conceptuales y jurídicos. Reflexiones para el uso sensato del patrimonio», en COLOMER, A. (Coord.) La ciudad elemento de identidad y factor de desarrollo del Mediterraneo. Historia y perspectivas, Ayuntamiento de Xátiva y Generalitat Valenciana, Xátiva, pp. 69-91.

TROITIÑO VINUESA, M. A. (1998): «Patrimonio arquitectónico, cultura y territorio», en Ciudades, n. 4, Valladolid, pp. 95-104. 